\section{Commentary: To ECMO or not to ECMO: That is the question}

\author{
Berhane Worku, MD, and Mario Gaudino, MD
}

In the current issue of the Journal, Hayanga and colleagues ${ }^{1}$ use the Nationwide Inpatient Sample database to assess hospital charges and outcomes after extracorporeal membrane oxygenation (ECMO) in more than 15,000 patients based on indication and time period. ECMO in the perioperative period for heart (HT) and lung transplant (LT) resulted in the longest length of stay and duration of ECMO support and, not surprisingly, carried the greatest charges per patient by far $(\sim 1.5$ million USD). ECMO for postcardiotomy shock (PCS) and cardiogenic shock (CS) resulted in shorter length of stay and duration of ECMO support and carried lower per-patient charges. However, cumulative charges were greatest for PCS and CS due to the significantly greater overall use of ECMO for these indications. Furthermore, in-hospital mortality was greatest for these latter indications. This study raises several cost-effectiveness and ethical considerations that must be eventually incorporated into decision making with regards to ECMO use.

ECMO can provide lifesaving potential in the setting of otherwise-fatal cardiac or respiratory failure. However, the significant costs, resource use, and prolongation of futility with the associated emotional burden placed on family are major drawbacks. ${ }^{2}$ Although such scenarios were once anecdotal rare events, they are now commonplace. Recent attempts to alter ECMO reimbursement highlight the increasing burden placed on the health care

\footnotetext{
From the Department of Cardiothoracic Surgery, Weill Cornell Medical Center, New York, NY.

Disclosures: The authors reported no conflicts of interest.

The Journal policy requires editors and reviewers to disclose conflicts of interest and to decline handling or reviewing manuscripts for which they may have a conflict of interest. The editors and reviewers of this article have no conflicts of interest.

Received for publication Feb 19, 2020; revisions received Feb 19, 2020; accepted for publication Feb 20, 2020; available ahead of print March 20, 2020.

Address for reprints: Mario Gaudino, MD, Department of Cardiothoracic Surgery, Weill Cornell Medical Center, 525 East 68th St, m-404, New York, NY 10065 (E-mail: Mfg9004@med.cornell.edu).

JTCVS Open 2020;1:71-2

2666-2736

Copyright (C) 2020 by The Authors. Published by Elsevier Inc. on behalf of The American Association for Thoracic Surgery. This is an open access article under the CC BY-NC-ND license (http://creativecommons.org/licenses/by-nc-nd/4.0/).

https://doi.org/10.1016/j.xjon.2020.02.004
}

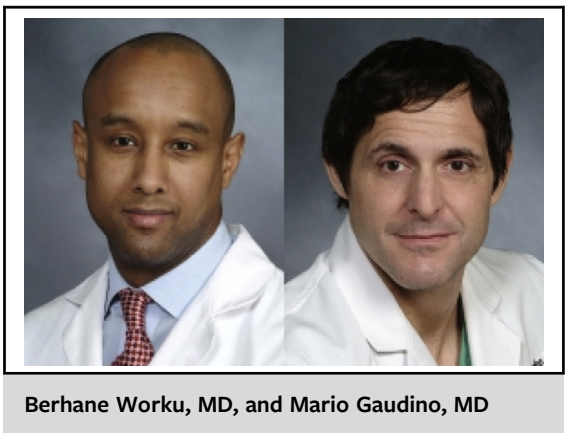

CENTRAL MESSAGE

Given the significant costs of extracorporeal membrane oxygenation and the highly variable outcomes associated with this heroic therapy, standardization of indications and management is mandatory.

economy by the proliferation of ECMO use. ${ }^{3}$ In the setting of PCS after elective heart surgery and primary graft dysfunction after HT and LT, ethical considerations may frequently "mandate" ECMO support when needed in patients who were otherwise "good enough" to take to the operating room in the first place, hence these being the original indications for ECMO. However, in the growing population of patients with CS and acute respiratory failure in whom iatrogenic etiologies are less frequently in play, more conventional algorithms incorporating risk/benefit and cost-effectiveness may be applied to ECMO use more liberally. ${ }^{4-6}$

The current study highlights the discrepancies in cost effectiveness of current ECMO practices, as the greatest cumulative charges are seen in patients with the greatest mortality (PCS and CS). However, several significant limitations exist as noted by the authors, including lack of any granularity of data with use of an administrative dataset such as the Nationwide Inpatient Sample (ie, patients with veno-arterial and veno-venous ECMO are not differentiated). Furthermore, hospital charges, not ECMO costs, are analyzed. This is the most significant limitation, as ECMO use likely contributes a small fraction to the cost of a HT or LT hospitalization, whereas it may significantly increase the cost of a CS or acute respiratory failure hospitalization. In the absence of cost data, incremental charges associated with ECMO 
(compared with patients with similar disease states not treated with ECMO) may be more relevant. Regardless, standardization of ECMO indications, management, and criteria for and timing of withdrawal of care in the setting of futility are desperately needed in this era of ECMO expansion.

\section{References}

1. Hayanga JWA, Aboagye J, Bush E, Canner J, Hayanga HK, Klingbbeil A, et al. Contemporary analysis of charges and mortality in the use of extracorporeal membrane oxygenation: a cautionary tale. J Thorac Cardiovasc Surg Open. 2020;1: 61-70.
2. Han JJ, Swain JD. The perfect ECMO candidate. J Am Coll Cardiol. 2018;71: 1176-7.

3. Keebler ME, Haddad EV, Choi CW, McGrane S, Zalawadiya S, Schlendorf KH, et al. Venoarterial extracorporeal membrane oxygenation in cardiogenic shock. JACC Heart Fail. 2018;6:503-16.

4. Schmidt M, Burrell A, Roberts L, Bailey M, Sheldrake J, Rycus PT, et al. Predicting survival after ECMO for refractory cardiogenic shock: the survival after venoarterial ECMO (SAVE)-score. Eur Heart J. 2015;36:2246-56.

5. Muller G, Flecher E, Lebreton G, Luyt CE, Trouillet JL, Bréchot N, et al. The ENCOURAGE mortality risk score and analysis of long-term outcomes after VA-ECMO for acute myocardial infarction with cardiogenic shock. Intensive Care Med. 2016;42:370-8.

6. Schmidt M, Zogheib E, Roze H, Repesse X, Lebreton G, Luyt CE, et al. The PRESERVE mortality risk score and analysis of long-term outcomes after extracorporeal membrane oxygenation for severe acute respiratory distress syndrome. Intensive Care Med. 2013;39:1704-13. 